\title{
Mean platelet volume as diagnostic and therapeutic marker of risk and prognosis of heart disease
}

\author{
Henshaw Uchechi Okoroiwu, Christopher Ogar Ogar \\ Hematology Unit, Department of Medical Laboratory Science, University of Calabar, Nigeria
}

\begin{abstract}
Increased mean platelet volume (MPV) is associated with platelet reactivity and is a predictor of cardiovascular risk and unprovoked nervous thromboembolism. Mean platelet volume is a precise measure of platelet size. Studies have reported the use of MPV as a biomarker for predicting ischemic stroke in atrial fibrillation patients as well as in anticoagulant prescription and rhythm-control therapy. Moreover, MPV may predict cardiovascular event outcome following percutaneous coronary intervention in patients with coronary artery disease. MPV may predict residual platelet reactivity in dual antiplatelet therapy. Factors influencing MPV result were discussed. This review centered on the reports that MPV may be a biomarker of risk and prognosis of prevalent heart diseases.
\end{abstract}

\section{Introduction}

Platelets are small anucleated cytoplasmic bodies circulating in the blood stream. These cellular fragments are derived from megakaryocytes in the bone marrow. ${ }^{1}$ In a steady state, megakaryocytopoiesis supplies about $10^{11}$ platelets per day with a new turnover every 8-9 days. However, this process is influenced by various environmental changes. Platelets normally circulate at concentration of $150-400 \times 10^{9} / \mathrm{L}$. $^{2,3}$

Platelets contain many organelles, a microtubular

Correspondence: Henshaw Uchechi Okoroiwu, Hematology Unit, Department of Medical Laboratory Science, University of Calabar, Nigeria.

Tel.: +234.8038833901.

E-mail: okoroiwuhenshaw@gmail.com

Key words: Mean platelet volume; cardiovascular disease; atrial fibrillation; myocardial infarction; biomarker.

Contributions: HUO conceived the study; HUO, COO performed literature search, downloads and wrote the manuscript. All authors read and approved the final manuscript.

Conflict of interest: the authors declare no conflict of interest.

Received for publication: 20 August 2017.

Accepted for publication: 15 December 2017.

This work is licensed under a Creative Commons Attribution NonCommercial 4.0 License (CC BY-NC 4.0).

CCopyright H.U. Okoroiwu and C.O. Ogar, 2018

Licensee PAGEPress, Italy

Italian Journal of Medicine 2018; 12:10-14

doi:10.4081/itjm.2018.918 system, a metabolically active membrane and consist mainly of three types of granules: $\alpha$-granules contain the von Willebrand factor, platelet-derived growth factor, platelet factor 4 and $\beta$-thrombomodulin. They are the most abundant granules in platelets and are rapidly exocytosized upon activation to enhance hemostasis and inflammation. The dense bodies contain adenosine nucleotides [adenosine diphosphate (ADP) and adenosine triphosphate (ATP)], calcium and serotonin, which induce platelet aggregation, vasoconstriction, cytokine production and modulators of inflammation. The lysosomes contain glycohydrolases and proteases that can aid in pathogen clearance, breakdown of extracellular matrix and contribute in clearance of platelet thrombi and degradation of heparin. ${ }^{1-5}$

Platelets play critical roles in the progression of thrombosis, atherosclerotic lesions and plaque destabilization; they express and secrete many substances that are crucial mediators of coagulation, inflammation and atherosclerosis. ${ }^{3,4}$ Larger platelets are metabolically and enzymatically more active than smaller ones and exhibit greater thrombotic potential. ${ }^{6-8}$ More so, increased platelet size is associated with other markers of activity such as platelet aggregation, enhanced thromboxane synthesis and $\beta$-thromboglobulin release and increased expression of adhesion molecules. ${ }^{7}$ Hence, platelet volume is thought to be predictive of cardiovascular diseases. ${ }^{9}$ Mean platelet volume (MPV) has been preferentially explored as marker of platelet reactivity and various diseases partly due to its inexpensive nature. It is part of the component of the complete blood count routinely run with automated hemo analyzers. This review sets off to illuminate the role of mean platelet volume as a biomarker of the risk and prognosis of cardiovascular disease and cardiac events. 
Mean platelet volume as a biomarker of the risk and prognosis of coronary artery disease

Mean platelet volume has been reported as potential tool in predicting patients who may develop coronary artery disease after primary percutaneous intervention. ${ }^{10}$ Diverse studies have centered on the role of MPV in predicting cardiovascular events, prediction of clinical outcome of patients undergoing dual antiplatelet therapy.

\section{Mean platelet volume as a biomarker for acute myocardial infarction}

Acute myocardial infarction occurs due to coronary atherosclerosis as well as thrombosis. ${ }^{11}$ When atherosclerotic plaque ruptures or erode, platelets are recruited to the exposed subendothelial region and the partially occluded vessels become completely occluded with the new formed thrombus. Large platelets have greater thrombotic potential and are biologically more potent. ${ }^{12}$ Increased platelet volume has been shown to be more reactive with greater production of thromboxane $\mathrm{A}_{2}$ and serotonin. Studies have reported platelet volume to be significantly higher among acute myocardial infarction patients than control subjects. ${ }^{13,14}$ An elevated MPV correlates with poor clinical outcomes among survivors of myocardial infarction in the era of thrombolysis and an impaired response to thrombolysis in those with ST segment elevated myocardial infarction. ${ }^{15}$ Elevated MPV has also been reported has also been reported to carry worse prognosis in terms of poor angiographic reperfusion and higher six months mortality following primary percutaneous coronary intervention (PCI) and also correlates with subsequent mortality and nonfatal myocardial reinfarction. ${ }^{16}$

\section{Mean platelet volume as prognostic tool in percutaneous coronary intervention outcome}

MPV has been reported as a useful biomarker in early identification of patients with stable coronary artery disease at high risk of post-PCI low-reflow. Studies have shown that pre-procedural elevated MPV is associated with the incidence of major adverse cardiac event and restenosis following PCI. ${ }^{17}$ The study submitted that MPV is a potential marker of restenosis after PCI. Another study reported that MPV independently predicted post-PCI-corrected thrombolysis in myocardial infarction frame count. ${ }^{18}$ It was suggested that monitoring MPV after PCI might aid in risk classification.

\section{Mean platelet volume and residual platelet interference in dual antiplatelet therapy}

Antiplatelet therapy is used to reduce the incidence of procedural-related complication as well as ischemic cardiovascular events in patients undergoing PCI.${ }^{19}$ High on-treatment platelet reactivity is associated with 2-9fold increased risk of recurrent ischemic events among patients receiving dual anti-platelet therapy for coronary artery disease. ${ }^{20}$ The high residual platelet reactivity can limit the overall utility of antiplatelet therapy.

\section{Mean platelet volume as a biomarker of ischemic stroke in atrial fibrillation patients}

Mean platelet volume has been identified as a biomarker of adverse cardiovascular events in atrial fibrillation (AF). These could be viewed in the role as predictor of ischemic stroke, guide towards rhythm or rate control tools in AF patients as well as guide in anticoagulant therapy.

\section{Mean platelet volume predictor of stroke risk}

Several studies have reported significant higher MPV in AF patients than in the control subjects. ${ }^{21,22}$ There is a positive association between MPV and the severity of acute ischemic stroke $\mathrm{e}^{23}$ and in predicting the risk of ischemic stroke in patients with atrial fibrillation. ${ }^{24-26}$ Butterworth and Bath ${ }^{27}$ reported that platelet volume is increased in patients with acute ischemic stroke. O'malley et al.$^{28}$ reported high values of MPV in all subtypes of ischemic stroke. Greisenegger et al. ${ }^{29}$ observed that an elevated MPV is associated with worst outcome for acute ischemic cerebral events independent of other clinical parameters. Another casecontrol study reported that stroke patients with AF had higher MPV than AF patients without stroke history. ${ }^{23}$ The exact mechanism underlying this supposed relationship is not yet clearly understood. However, it has been suggested to be due to the association between MPV and markers of left atrial stasis, reinforcing the notion that cardioembolic mechanism may be in play when $\mathrm{AF}$ is associated with stroke. ${ }^{29}$

\section{Mean platelet volume as a guide in therapy selection in atrial fibrillation treatment}

There are two approaches to the treatment of atrial fibrillation; cardioversion and treatment with antiarrhythmic drugs to maintain sinus rhythm and use of rate-controlling drugs, allowing atrial fibrillation to persist. ${ }^{30}$ Although studies on difference in mortality in the two methods were reported to have no difference. ${ }^{30-32}$ However, Hong et al..$^{33}$ demonstrated that MPV and the rate control strategy for treatment of AF were predictive markers for stroke.

\section{Mean platelet volume as anticoagulant therapy guide in atrial fibrillation}

Anticoagulant therapy and antiplatelet agents reduce stroke by $60 \%$ and $20 \%$, respectively in patients 
with atrial fibrillation. Judicious use of antithrombotic therapy importantly reduces stroke for most patients who have atrial fibrillation. ${ }^{34}$ In view of this, identifying patients with high risk of ischemic stroke is important in the management of AF patients. Mean platelet volume has been shown to enhance predictive value of the clinical variables employed when calculating $\mathrm{CHAD}_{2}$ or $\mathrm{CHA}_{2} \mathrm{DS}_{2}$ VASc scores. ${ }^{24} \mathrm{Ha}$ et al. ${ }^{24}$ reported that patients with high MPV who were not on anticoagulation therapy had poorer stroke-free survival than did others, even for those with $\mathrm{CHAD}_{2}$ score of $<2$. It was suggested that anticoagulation therapy was required by patients with high MPVs. ${ }^{24}$

\section{Possible mechanisms of action of mean platelet volume in cardiovascular diseases}

Although the exact mechanism by which elevated MPV influences the progression of cardiovascular diseases is not completely clear, multiple mechanisms may be involved. However, some postulations have been offered. Larger platelets are metabolically and enzymatically more active than smaller ones, containing more prothrombotic materials, with increased thromboxane $\mathrm{A}_{2}$ and $\mathrm{B}_{2}$ and glycoprotein IIb-IIIa receptor expression. ${ }^{35,36}$ They show decreased inhibition of aggregation by prostacyclin and greater aggregability in response to ADP in vitro. ${ }^{37}$ Larger platelets are denser and contain more $\alpha$-granules which release thrombotic substances including platelet factor $4,{ }^{38} \mathrm{P}$ selectin $^{35}$ and platelet derived growth factor, ${ }^{39}$ a chemotactic and mitogenic factor contributing to vascular neointimal proliferation. ${ }^{40}$ More so, larger platelets are more often reticulated and this is an independent predictor of poor response to dual antiplatelet therapy. ${ }^{41}$

\section{Factors influencing mean platelet volume results}

Certain preanalytical factors can affect the result of MPV if not properly followed.

\section{Venipuncture, filling and mixing}

Careful and non-prolonged venipuncture is required for sample meant for MPV. Inaccurate venipuncture, filling of tube and mixing may result in platelet activation and produce clumping, hence, giving wrong result.

\section{Choice of anticoagulant}

To inhibit coagulation of blood for hematological samples before analysis, anticoagulants are used. EDTA or sodium citrate are standard substances. Both bind calcium in an irreversible (EDTA) or reversible (sodium citrate) manner. Platelets will swell and continue to do so due to anticoagulants. ${ }^{42}$

Specifically, EDTA causes ultra-structural morphological changes in platelets. ${ }^{43} \mathrm{Na}-\mathrm{EDTA}$ as an anticoagulant, results in less pronounced swelling than K-EDTA. ${ }^{44}$ More so, sodium citrate results in more distinct swelling in low concentration $(0.12 \mathrm{mmol} / \mathrm{mL}$, ratio 9:1, blood to citrate) and almost no swelling in high concentration citrate $(0.12 \mathrm{mmol} / \mathrm{mL}$, ratio $4: 1$, blood to citrate). ${ }^{45}$

\section{Time interval of measurement}

Time interval is negligible in high concentration $\mathrm{Na}_{3}$-citrate (1:4, citrate to blood) anticoagulated sample whereas low concentration of $\mathrm{Na}_{3}$-citrate (1:9, citrate to blood), and K-EDTA samples are best analyzed between 60 and $90 \mathrm{~min}$, respectively, from the time of collection. ${ }^{45,44}$ Some studies recommend measurement within 1 hour regardless of anticoagulant used. ${ }^{46}$

\section{Sample storage temperature}

Some studies have reported that cooling citrate blood sample tubes from $37^{\circ} \mathrm{C}$ to $4^{\circ} \mathrm{C}$ increases mean platelet volume results by $18 \% .{ }^{47,48}$

\section{Limitations}

Some limitations of this review are that the literature search was limited to association of MPV with cardiovascular disease. This might be a limitation. Moreover, most relevant studies reported have been retrospective in nature and involved small number of patients.

\section{Conclusions}

Several researchers have reported correlation between the risk of ischemic stroke in atrial fibrillation patients and elevated MPV following PCI in coronary heart diseases. MPV value can guide the physician on the risk of restenosis following PCI. MPV as a marker can provide an insight on therapy selection in AF patients as well as residual platelet reactivity in dual platelet therapy.

\section{References}

1. Smyth SS, Whiteheart S, Italiano JE, Coller BS. Williams hematology. Chapter 114: Platelet morphology, biochemistry and function. Chicago, IL: McGrawHill; 2010. pp 1735-1814.

2. Harrison P, Keeling D. Laboratory hematology practice. Chapter 37: Platelet assays and platelet dysfunction. Chicago, IL: McGraw-Hill; 2012. pp 480-491. 
3. Coppinger ZA, Cagney G, Toomey S, et al. Characterization of the proteins released from activated platelet led to localization of novel platelet protein of human atherosclerosis lesion. Blood 2004;104:2096-104.

4. Gawaz M, Langer H, May AE. Platelet in inflammation and atherogenesis. J Clin Invest 2005;115:3378-84.

5. Jenne CN, Urrutia R, Kubes P. Platelets: bridging hemostasis, inflammation and immunity. Int J Lab Hematol 2013;35:254-61

6. Kamath S, Blann AD, Lip GY. Platelet activation: assessment and quantification. Eur Heart J 2001;22:1561-71.

7. Bath PM, Butherworth RJ. Platelet size: measurement, physiology and vascular disease. Blood Coagul Fibrinolysis 1996; 7:157-61.

8. Okoroiwu HU, Atangwho IJ, Uko EK, Okafor IF. Haemostatic property of Chromolaena odorata leaf extracts: in vitro and in vivo evaluation in Wistar rats. J Biol Res 2016;89:56-60.

9. Tsiara S, Elisaf M, Jagroop IA, Mikkhailidis DP. Platelet as predictors of vascular risks: Is there a practical index of platelet activity? Clin Appl Thromb Hemost 2003;9: $177-90$

10. Choi DH, Kang S, Song H. Mean platelet volume: a potential biomarker of the risk and prognosis of heart diseases. Korean J Intern Med 2016;31:1009-17.

11. Jorgensen KA, Dyerberg J. Platelets and atherosclerosis. A review on the role of platelets in atherosclerosis with special reference to the role of polyunsaturated 20 carbon. Dan Med Bull 1980;27:253-9.

12. Agrawal BK, Manchanda B, Garg A, et al. Mean platelet volume in acute myocardial infarction: a case-control study. J Cardiovasc Res 2015;1:4.

13. Khode V, Sindhur J, Kanbur D, et al. Mean platelet volume and the platelet volume indices in patient with stable coronary artery disease and acute myocardial infarction: a case-control study. J Cardiovasc 2012;3: 272-6.

14. Chu SG, Becker RC, Berger PB, et al. Mean platelet volume as a predictor of cardiovascular risk: a systematic review and meta-analysis. J Thromb Haemost 2010;8: 148-56.

15. Pereg D, Berlin T, Mosseri M. Mean platelet volume on admission correlates with impaired response to thrombolysis in patients with ST-elevated myocardial infarction. Platelets 2010;21:117-21.

16. Martin J, Balt PM, Burr MI. Increased platelet size following myocardial infarction is associated with subsequent death and nonfatal reinfarction. Lancet 1991;338: 1409-11.

17. Yang A, Pizzulli I, Luderitz B. Mean platelet volume as marker of restenosis after percutaneous transluminal coronary angioplasty in patients with stable and unstable angina pectoris. Thromb Res 2006;117:371-7.

18. Duygu H, Turkoglu C, Kirilmaz B, Turk U. Effects of mean platelet volume on post-intervention coronary blood flow in patients with chronic stable angina pectoris. J Invasive Cardiol 2008;20:120-4.

19. Shanker J, Gasparyan AY, Kitas GD, Kakkar VV. Platelet function and antiplatelet therapy in cardiovascular disease implications of genetics polymorphisms. Curr Vasc Pharamacol 2011;9:479-89.

20. Verdoia M, Patrizia P, Rolla R, et al. Mean platelet volume and high-residual platelet reactivity in patient re- ceiving dual antipaltelet therapy with clopidogrel or ticagrelor. Exp Opin Pharmacother 2015;16:1739-47.

21. Feng C, Mei W, Luo C, et al. Relationship between mean platelet volume and coronary blood flow in patients with atrial fibrillation. Heart Lung Circ 2013; 22:43-9.

22. Colkesen Y, Acil T, Abayli B, et al. Mean platelet volume is elevated during paroxysmal atrital fibrillation: A marker of increased platelet activation. Blood Coagul Fibrinol 2008;19:411-4.

23. Greisenegger S, Endler G, Hsieh K, et al. Is elevated mean platelet volume associated with worse outcome in patients with acute ischemic cerebrovascular events? Stroke 2004;35:1688-91.

24. Ha SI, Choi DH. Stroke prediction using mean platelet volume in patients with atrial fibrillation. Platelet 2011;22:408-14.

25. Turfan M, Erdogan E, Ertas G, et al. Usefulness of mean platelet volume for predicting stroke risk in atrial fibrillation patients. Blood Coagul Fibrinolysis 2013; 24:55-8.

26. Xu XF, Jiang FL, Ou MJ, Zhang ZH. The association between mean platelet volume and chronic atrial fibrillation and the presence of thrombotic events. Biomed Rep 2015;3:388-94.

27. Butherworth RJ, Bath PM. The relationship between mean platelet volume, stroke subtype and clinical outcome. Platelet 1998;9:359-64.

28. O'malley T, Langhorne P, Elton RA, Stewart C. Platelet size in stroke patients. Stroke 1995;26:995-9.

29. Providential R, Faustino A, Paiva L, et al. Mean platelet volume is associated with the presence of left atrial stasis in patients with non-valvular atrial fibrillation. BMC Cardiovasc Disord 2013;13:40.

30. Wyse DG, Waldo AL, Dimarco JP, et al. A comparison of rate control and rhythm control in patients with atrial fibrillation. N Engl J Med 2002;347:347.

31. Van Gelder IC, Hagens VE, Bosker HA, et al. A comparison of rate control and rhythm control in patients with recurrent persistent atrial fibrillation. N Engl J Med 2002;347;1834-40.

32. Hohnloser SH, Kuck KH, Lilienthal J. Rhythm or rate control in atrial fibrillation. Pharmacological Intervention in Atrial Fibrillation (PIAF): a randomized trial. Lancet 2000;356:1789-94.

33. Hong SP, Choi DH, Kim HW, et al. Stroke prevention in patients with non-valvular atrial fibrillation: new insight in selection of rhythm or rate control therapy and impact of mean platelet volume. Curr Pharm Des 2013; 19:5824-9.

34. Hart RG, Pearce LA, Anguilar MI. Meta-analysis: antithrombotic therapy to prevent strokes in patients who have non-valvular atrial fibrillation. Ann Inten Med 2007; 146:857-67.

35. Kamath S, Blann AD, Lip GY. Platelet activation: assessment and quantification. Eur Heart J 2001;22:1561-71.

36. Giles H, Smith RE, Martin JL. Platelet glycoporotein IIb-IIIa and size are increased in acute myocardial infarction. Eur J Clin Invest 1994;24:448-98.

37. Jakubowski JA, Adler B, Thomson CB, et al. Influence of platelet volume on the ability of prostacyclin to inhibit platelet aggregation and the release reaction. J Lab Clin Med 1985;105:271-6. 
38. Martin JF, Shaw T, Heggie J, Pennington DG. Measurement of the density of human platelets and its relationship to volume. Br J Haematol 1983;54:337-52.

39. Casscells W. Smooth muscle cell growth factor. Prog Growth Factor Res 1991;3:177-206.

40. Ferns GA, Raines EW, Sprugel KH, et al. Inhibition of neointimal smooth muscle accumulation after angioplasty by an antibody of PDGF. Science 1991;253:1129-32.

41. Guthikonda S, Alviar CL, Vaduganatham M, et al. Role of reticulated platelet and platelet size heterogeneity on platelet activity after dual antiplatelet therapy with aspirin and clopidogrel in patients with stable coronary artery disease. J Am Coll Cardiol 2008;52:743-9.

42. Lance MD, Sloep M, Hensken YM, Marcus MA. Mean platelet volume as a diagnostic marker for cardiovascular disease: draw back of preanalytical conditions and measuring techniques. Clin Appl Thromb Hemost 2012 [Epub ahead of print].
43. White JG, Escolar G. EDTA-induced changes in platelet structure and function: adhesion and spreading. Platelet 2000;11:56-61.

44. Thompson CB, Diaz DD, Quinn PG, et al. The role of anticoagulation in the measurement of platelet volumes. Am J Clin Pathol 1983;80:327-32.

45. Bath PM. The routine measurement of platelet size using sodium citrate as the anticoagulant. Thromb Haemost 1993;70:687-90.

46. Dastjerdi MS, Emami T, Najafian A, Amini M. Mean platelet volume measurement, EDTA or citrate? Hematology 2006;11:317-9.

47. Park Y, Schoene N, Harris W. Mean platelet volume as an indicator of platelet activation: methodological issues. Platelets 2002;13:301-6.

48. Threatte GA, Adrados C, Ebbe S, Brecher G. Mean platelet volume: the need for reference method. Am J Clin Pathol 1984;81:769-72. 